University of Nebraska - Lincoln

DigitalCommons@University of Nebraska - Lincoln

Sociology Department, Faculty Publications

Sociology, Department of

2019

\title{
Understanding Daily Depression, Drinking, and Marijuana Use Among Homeless Youth Using Short Message Service Surveying
}

\author{
Kimberly A. Tyler \\ University of Nebraska - Lincoln, kim@ktresearch.net \\ Kristen M. Olson \\ University of Nebraska - Lincoln, kolson5@unl.edu \\ Colleen M. Ray \\ University of Nebraska-Lincoln
}

Follow this and additional works at: https://digitalcommons.unl.edu/sociologyfacpub

Part of the Family, Life Course, and Society Commons, and the Social Psychology and Interaction

Commons

Tyler, Kimberly A.; Olson, Kristen M.; and Ray, Colleen M., "Understanding Daily Depression, Drinking, and Marijuana Use Among Homeless Youth Using Short Message Service Surveying" (2019). Sociology Department, Faculty Publications. 747.

https://digitalcommons.unl.edu/sociologyfacpub/747

This Article is brought to you for free and open access by the Sociology, Department of at DigitalCommons@University of Nebraska - Lincoln. It has been accepted for inclusion in Sociology Department, Faculty Publications by an authorized administrator of DigitalCommons@University of Nebraska - Lincoln. 


\title{
Understanding Daily Depression, Drinking, and Marijuana Use Among Homeless Youth Using Short Message Service Surveying
}

\author{
Kimberly A. Tyler, Kristen Olson and Colleen M. Ray
}

University of Nebraska-Lincoln, Lincoln, NE, USA

Correspondence - Kimberly A. Tyler kim@ktresearch.net Department of Sociology, University of Nebraska-Lincoln, 717 Oldfather Hall, Lincoln, NE, 68588-0324, USA.

\begin{abstract}
We used short message service surveying (SMS) with 150 homeless youths to examine the time ordering of feeling depressed with drinking alcohol, using marijuana, and using substances with friends. Multilevel binary logistic regression results revealed that youths who were depressed earlier in the day were more likely to drink alcohol later that day. Among depressed youths, heterosexual youths were less likely to drink alcohol than lesbian, gay, and bisexual (LGB) youths. Depressed youths had increased odds of using marijuana by a factor of 1.6, while heterosexual youths, compared to LGB youths, were $80 \%$ less likely to use marijuana. Females were $82 \%$ less likely and heterosexual youths $75 \%$ less likely to use substances with friends compared to males and LGB youths, respectively. These findings improve upon prior retrospective studies by using SMS to understand time ordering between feeling depressed and substance use in the same day.
\end{abstract}

Keywords: alcohol, homeless youth, marijuana, peers, short message service surveying

Published as: Kimberly A. Tyler, Kristen Olson \& Colleen M. Ray (2019) Understanding Daily Depression, Drinking, and Marijuana Use Among Homeless Youth Using Short Message Service Surveying, Journal of Child \& Adolescent Substance Abuse, 28:3, 170-179, DOI: 10.1080/1067828X.2019.1667286

Copyright (C) 2019 Taylor \& Francis Group, LLC. Used by permission.

Published 25 September 2019. 
According to the National Network for Youth (2018), between 1.3 and 1.7 million youths have experienced at least one night of being homeless within a specific year. Furthermore, "Youth are the fastest growing segment of people experiencing homelessness and may be at greater risk for homelessness than any other age group" (Substance Abuse and Mental Health Services Administration [SAMHSA], 2016, p. 1). Youths experiencing homelessness have high rates of substance use (Hadland et al., 2011) and poor mental health such as depression (Brown, Begun, Bender, Ferguson, \& Thompson, 2015), and substance use and depression are positively associated (Hadland et al., 2011). If left unchecked, substance use may lead to further adverse mental health consequences (Kidd \& Carroll, 2007) and prolonged substance misuse (Thompson, Bender, Ferguson, \& Kim, 2015).

Although research shows a positive association between depression and substance use among homeless youths (Hadland et al., 2011), studies are generally cross-sectional and retrospective; thus, researchers are unable to disentangle the time ordering of these events. Furthermore, it is unknown whether a specific depressive episode earlier in the day is linked to drinking and drug use later that day and whether this varies by gender and sexual orientation. The current study addresses this literature gap by using ecological momentary assessment (EMA) via short message service (SMS) surveying over a 30-day period with homeless youths to examine whether being depressed earlier in the day is associated with youths drinking alcohol, using marijuana, and using substances with their friends later that day. EMA allows the researcher to capture data on a specific behavior or feeling when it occurs in their natural environment (Shiffman, Stone, \& Hufford, 2008). EMA via SMS surveys verifies the timing of one behavior relative to another, allowing for temporal sequencing (Cohn, Hunter- Reel, Hagman, \& Mitchell, 2011), and minimizes recall biases (Kuntsche \& Labhart, 2013). Given the high mobility of homeless youths (Tyler \& Whitbeck, 2004), using SMS to collect daily data from this group is innovative and an improvement over prior retrospective studies of homeless youths. Moreover, understanding whether being depressed earlier in the day is linked with specific drinking and drug use episodes later that day and whether this varies by gender and sexual orientation has important implications for agencies serving this population, such as being able to more effectively intervene to lower the risk for substance use. 


\section{Literature review}

\section{Rates of substance use}

It is estimated that youths experiencing homelessness use substances 2 to 3 times more compared to their stably housed peers (Kipke, Montgomery, \& MacKenzie, 1993; Thompson, 2005). Moreover, 75\% of youths experiencing homelessness report lifetime alcohol and/or marijuana use (Bousman et al., 2005; Walls \& Bell, 2011) whereas past- 30-day prevalence rates for alcohol and marijuana usage have been found to be $68 \%$ and 66\%, respectively (Wenzel, Tucker, Golinelli, Green, \& Zhou, 2010). Santa Maria and colleagues (2018) found that 40 out of a total of 66 youths experiencing homelessness reported using drugs on at least one day in the prior 21 days and of these 40, 36 youths used marijuana, on average, a total of five days. Marijuana was the drug reported by youths as being used most often (Santa Maria et al., 2018). Lim, Rice, and Rhoades (2016) found that homeless youths used, on average, 2.45 different substances in the past 30 days with marijuana being used most frequently (73\%), followed by alcohol (69\%).

\section{Depression}

Homeless youths have been found to have high rates of depression (Brown et al., 2015; Hadland et al., 2011; Nyamathi et al., 2012). Brown and colleagues (2015), for example, found that more than one-third of their sample of more than 200 homeless youths met diagnostic criteria for major depression. In addition, in a study of homeless youths attending school, $47 \%$ of these youths reported feeling depressed in the past 12 months with males being significantly less likely to feel depressed compared to females (Moore, Benbenishty, Astor, \& Rice, 2018). Other research also finds that depression tends to be consistent over time (Tyler, Schmitz, \& Ray, 2018). The social circumstance of experiencing homelessness also increases risk for depression (Brown et al., 2015; Lim et al., 2016). Moreover, young people combating homelessness experience numerous psychological stressors such as depression that may place them at risk for substance misuse (Hadland et al., 2011; Lim et al., 2016; Nyamathi et al., 2012). 


\section{Substance-using friends}

The friends of homeless youths have been found to be influential in their substance use such that having more peers who use substances is positively associated with youths' own substance use (Rice, Milburn, Rotheram-Borus, Mallett, \& Rosenthal, 2005; Tyler, 2008b; Wenzel et al., 2010). Moreover, Rice and colleagues (2005) found that having a greater density of drug-using peers within a social network increased the likelihood that homeless youths themselves would use drugs. Similarly, Wenzel and colleagues (2010) found that youths who had a greater number of substance-using peers in their networks were more likely to drink alcohol and use marijuana more frequently. Other studies also support the positive link between the influence of peers with homeless youths' alcohol and other drug misuse (Tompsett, Domoff, \& Toro, 2013).

\section{Gender, sexual orientation, and age}

There is a paucity of research that has examined whether gender, sexual orientation, and/or age are associated with poorer health outcomes (Bao, Whitbeck, \& Hoyt, 2000; Cochran, Stewart, Ginzler, \& Cauce, 2002; Tyler, 2008b). Gender and sexual orientation can be sources of status strains that may be important for understanding risk factors for poor mental health and/or substance use (Tyler, 2008b; Tyler et al., 2018). Status strain occurs when majority and minority groups have differential access to power, prestige, and resources that improve or exacerbate the risk for detrimental health outcomes (Pearlin, 1999). Among homeless youths, sexual minorities experience unique stressors, such as having higher levels of depressive symptoms (Tyler, 2008a) compared to heterosexual homeless youths. Similarly, homeless female youths generally fare worse on mental health outcomes (Stewart et al., 2004), such as experiencing greater symptoms of depression, compared to their male counterparts (Bao et al., 2000). As such, we would expect the relationship between depression and substance use to vary by these characteristics.

Similarly, there is a lack of research on substance use by gender, age, and sexual orientation and the studies that do exist tend to have mixed results. That is, some studies find no differences in marijuana use (Wenzel et al., 2010) or other drug-related behaviors (Tyler, 2008b) by sexual orientation whereas one study found that heterosexual youths used 
more alcohol and drugs compared to lesbian, gay, and bisexual (LGB) youths (Santa et al., 2018). In terms of gender, while one study found no differences in usage rates for alcohol or marijuana (Wenzel et al., 2010), other research has found that males have higher rates of drug and alcohol use compared to females (Santa Maria et al., 2018; Tyler, 2008b). While even fewer studies have examined age differences, one study found a positive link between older age and engaging in more drug-related behaviors (Tyler, 2008b), while a second study found higher alcohol use among older-aged respondents but found no age difference by drug use (Santa et al., 2018). Given the lack of research and the inconsistent findings, more research is needed to better understand whether the link between feeling depressed and substance use varies by gender and sexual orientation.

\section{Current study}

Although prior research shows a positive link between depression and substance use among homeless youths (Hadland et al., 2011), studies are often cross-sectional and retrospective; thus, researchers are unable to disentangle the time ordering of these events. Moreover, it is unknown whether a specific depressive episode earlier in the day is linked to drinking and drug use later that day and whether this varies by gender and sexual orientation. To address these literature gaps, the current study uses EMA via SMS over 30 days with homeless youths to examine whether being depressed earlier in the day is associated with youths drinking alcohol, using marijuana, and using substances with their friends later that day.

\section{Method}

Data are from the Homeless Youth Texting Project, a pilot study designed to examine risk and protective factors for substance use and to field test EMA via SMS to ascertain its utility and feasibility with homeless youths. Findings from the feasibility study are reported elsewhere. From August 2014 through October 2015, 150 homeless youths were interviewed in two Midwestern cities. Of the 150 respondents interviewed at baseline, 
112 youths, or $75 \%$, completed a follow-up interview. The university institutional review board approved this study.

Eligibility required youths to be between 16 and 22 years of age and homeless or runaway. Homeless youths, as inclusively defined by the 2015 reauthorization of the McKinney-Vento Homeless Assistance Act, includes those who lack permanent housing such as spending the previous night in a shelter, public place, on the street, with friends, or in a transitional facility, or other places not intended as a domicile (National Center for Homeless Education, The (NCHE) and the National Association for the Education of Homeless Children and Youth (NAEHCY), 2017). All participants in the current study were unaccompanied youths, meaning they were not experiencing homelessness with family members or caregivers. Runaway includes those under age 18 who spent the previous night away from home without parental permission (Ennett, Bailey, \& Federman, 1999). Participants were recruited through three local agencies which offer emergency shelter, food programs, transitional living services, and street outreach.

Four trained and experienced interviewers conducted the interviews. Interviewers approached youths at shelters, food programs, and during street outreach. Informed consent was obtained from youths, who were told that the study had three parts and if they agreed to participate, they would need to complete a baseline structured interview, the SMS portion, and a follow-up, structured interview. The two interviews, which were conducted in shelter interview rooms, local library, or outside (weather permitting), lasted 45 minutes and 15 minutes, respectively. Participants received a $\$ 20$ and $\$ 10$ gift card to a local store for completing the baseline and follow- up interview, respectively. Less than $3 \%$ of youths $(\mathrm{N}=5)$ refused to participate or were ineligible.

\section{Cell phone distribution}

Upon completing the baseline interview, participants were given a disposable cell phone and told they would receive 11 texts per day over the next 28 to 30 days and then would be re-contacted in approximately 30 days for a follow-up interview. The blocks of texts came at 10:00 a.m., 4:00 p.m., and 9:30 p.m. Text questions were sent from an automated system, set up to send out text questions in the same order and at the same time each day. Responding to each text question required 
participants to enter a number(s). Typically, three or four days prior to the end of their texting period, youths were sent a text informing them how many texting days were left and to set up a follow-up interview. Those who responded to every text question (11 texts per day) were paid $\$ 50$ cash (prorated at $\$ 0.14$ per response) and those who responded to at least $85 \%$ of texts also received a bonus $\$ 10$ gift card.

\section{Measures}

\section{Text questions}

From the text data, we use one question asked at 4:00 p.m.: "Today I felt depressed or lonely." Approximately 15\% of youth-days with valid substance use data were missing a report on the depression question. Thus, the depression measure has three categories $(0=$ not depressed, 1 = depressed, 2 = missing depression text). Next, we use three questions that were asked at 9:30 p.m. for our dependent variables: (a) alcohol use: "how many drinks tonight" ( 1 = any drinks, 0 = no drinks); (b) marijuana use: "used any of these drugs tonight" (weed, crank, meth, coke, inhalant, heroin, ecstasy, other, none); from this list of drugs, we examine only marijuana (i.e., weed) for the current analyses ( $1=$ used marijuana; $0=$ did not use marijuana); and (c) substance use with peers: "drank or did drugs with friends tonight" ( 1 = yes, 0 = no). On eight days, youths indicated that they drank with friends, but failed to answer the question about the number of drinks tonight. These answers were imputed to a " 1 = any drinks" in the alcohol use question for that day.

\section{Survey questions}

From the survey data, we include the following variables: gender, which was coded 0 = male, 1 = female; sexual orientation, which was coded $0=\mathrm{LGB}, 1$ = straight or heterosexual; and age, which was a continuous variable that asked youths their current age at the time of the interview.

\section{Statistical analysis}

Each day of texting ( $i$ ) is nested within each youth $(j)$; thus, the data have a multilevel format. For three sets of models we predict $\operatorname{logit}\left(\operatorname{Pr}\left(y_{i j}=1\right)\right)$, where $y_{i j}=1$ when there was any (a) drinking, (b) 
marijuana use, or (c) substance use with friends reported on a given day using the melogit procedure in Stata 15.1. The sample size for each set of models varies due to missing data. Overall, 143 youths reported information about drinking on 2,061 youth-days, indicating that they drank on $7.81 \%$ of those days. For marijuana use, 139 youths reported information on 2,224 youth-days, and youths used marijuana on $15.38 \%$ of those youth-days. Finally, 138 youths reported information about their substance use with friends on 1,928 days, indicating that they used some form of substance with their friends $15.46 \%$ of those youth-days.

\section{Results}

\section{Sample characteristics}

Demographics based on wave 1 survey data included 150 homeless youths ages 16 to 22 years ( $\mathrm{M}=19.4$ years). One-half (51\%) were female, and $22 \%$ identified as LGB. In terms of substance use, $81 \%$ of youths reported lifetime marijuana use, $80 \%$ alcohol use, 23\% ecstasy/ designer drug use, 19\% cocaine use, and 18\% reported lifetime methamphetamine use. In terms of depression, using the Diagnostic and Statistical Manual of Mental Disorders (DSM) cutoff of $\geq 10,69 \%$ of study youths have clinically significant depressive symptoms. For the SMS data, youths reported being depressed on $22 \%$ of youth-days.

\section{Multivariate models}

Current-day drinking. Table 1 shows the results of multilevel binary logistic models for current-day drinking. The first model included all covariates without interactions. Model 2 included an interaction between current-day depression and gender (female), and Model 3 included an interaction between current-day depression and sexual orientation (hetero). In Model 1, both female and heterosexual youths were less likely to report drinking by $65 \%$ and $75 \%$, respectively, compared to their male and LGB counterparts.

Model 2 shows a significant interaction between gender and currentday depression. As displayed in Figure 1, among youths who were not depressed, males had a significantly greater probability of drinking that 
Table 1. Adjusted odds ratio (AOR) and confidence intervals (CI) predicting current-day drinking.

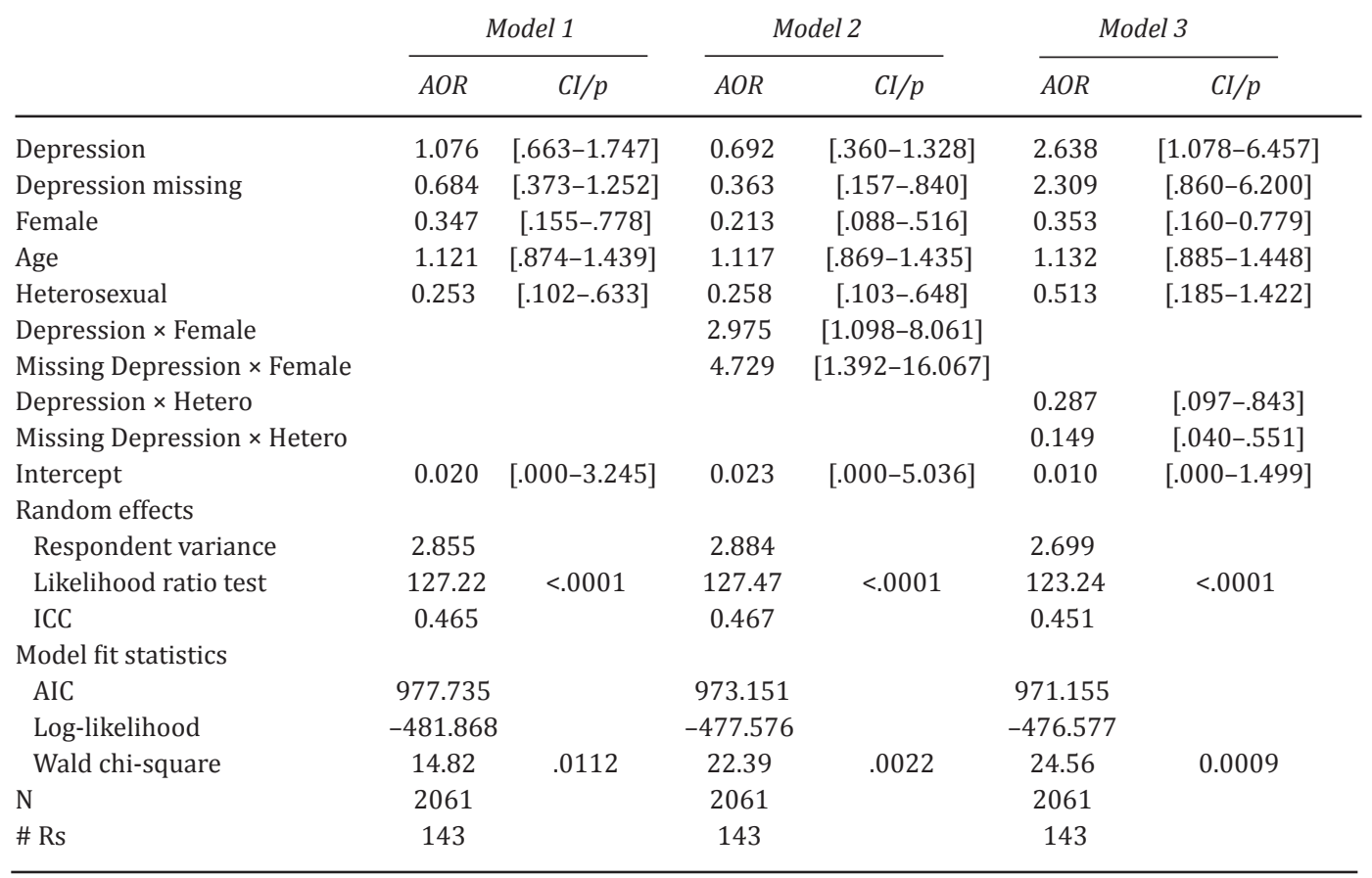

ICC = intraclass correlation coefficient; AIC = Akaike information criterion

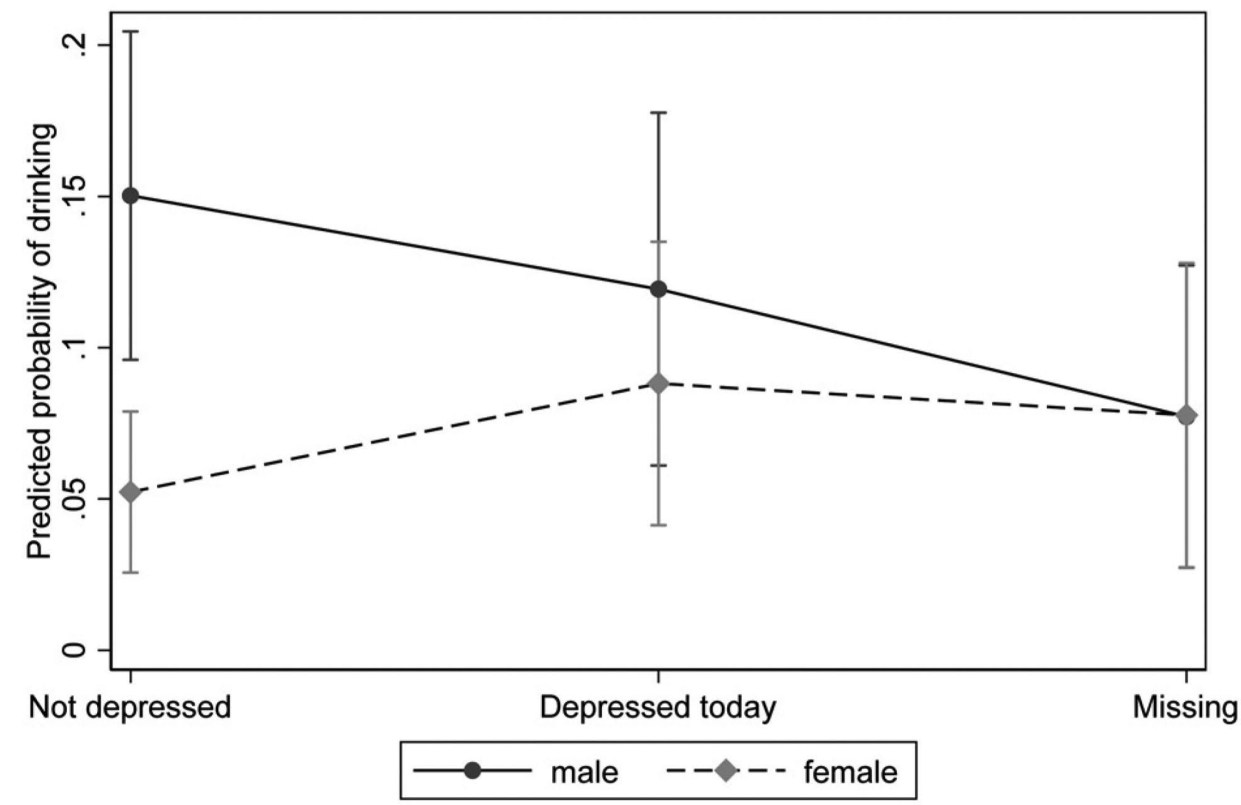

Figure 1. Interaction effect between depression and gender on drinking. 


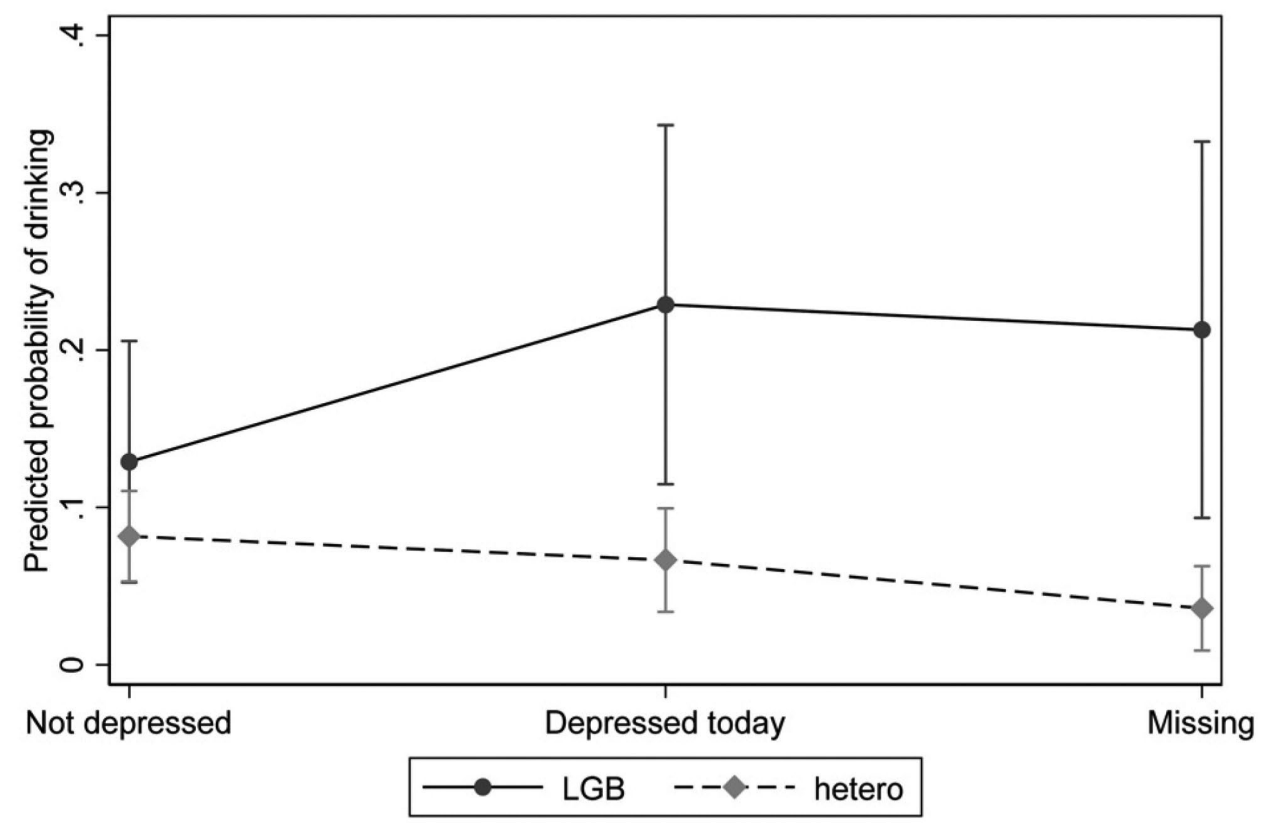

Figure 2. Interaction effect between depression and sexuality on drinking.

day compared to females. Among youths who were depressed that day, however, there were no significant differences in current-day drinking by gender. There were also no differences in reported drinking for youths who failed to answer the depression prompt.

Model 3 (Table 1) shows a significant interaction between sexual orientation and currentday depression. Among youths who were not depressed that day, there were no differences in the probability of drinking by sexual orientation. However, as shown in Figure 2, among youths who were depressed that day, LGB individuals were significantly more likely to drink alcohol that evening compared to their heterosexual counterparts, as were youths who failed to answer the depression question.

Current-day marijuana use. Table 2 shows the results of multilevel binary logistic models for current-day marijuana use, where Model 1 included all covariates without interactions, and Models 2 and 3 included interactions between current-day depression with gender and sexual orientation, respectively. Those that were depressed on that day had increased odds of using marijuana by a factor of 1.601 , while those that were heterosexual, compared to their LGB counterparts, were $80 \%$ less 
Table 2. Adjusted odds ratio (AOR) and confidence intervals (CI) predicting current-day marijuana use.

\begin{tabular}{|c|c|c|c|c|c|c|}
\hline & \multicolumn{2}{|c|}{ Model 1} & \multicolumn{2}{|c|}{ Model 2} & \multicolumn{2}{|c|}{ Model 3} \\
\hline & $A O R$ & $C I / p$ & $A O R$ & $C I / p$ & $A O R$ & $C I / p$ \\
\hline Depression & 1.601[ & [1.006-2.548] & 1.490 & {$[.796-2.790]$} & 1.593 & {$[.730-3.477]$} \\
\hline Depression missing & 1.246 & {$[.766-2.027]$} & 1.557[ & {$[.812-2.986]$} & 1.195 & {$[.510-2.798]$} \\
\hline Female & 0.350 & {$[.115-1.064]$} & 0.374 & {$[.116-1.201]$} & 0.350 & {$[.115-1.063]$} \\
\hline Age & 1.390 & {$[.980-1.971]$} & 1.393 & {$[.981-1.978]$} & 1.390 & {$[.980-1.972]$} \\
\hline Heterosexual & 0.201 & {$[.053-.764]$} & 0.204 & {$[.054-.777]$} & 0.198 & {$[.049-.800]$} \\
\hline Depression $\times$ Female & & & 1.152 & {$[.450-2.950]$} & & \\
\hline Depression missing $\times$ Female & & & 0.612[ & [0.228-1.646] & & \\
\hline Depression $\times$ Hetero & & & & & 1.002 & {$[.378-2.658]$} \\
\hline Depression missing $\times$ Hetero & & & & & 1.066 & [0.377-3.012] \\
\hline Intercept & 0.000 & {$[.000-.197]$} & 0.000 & {$[.000-.185]$} & 0.000 & {$[.000-.201]$} \\
\hline \multicolumn{7}{|l|}{ Random effects } \\
\hline Respondent variance & 11.231 & & 11.336 & & 11.242 & \\
\hline Likelihood ratio test & 668.58 & $<.0001$ & 669.24 & $<.0001$ & 661.61 & $<.0001$ \\
\hline ICC & 0.773 & & 0.775 & & 0.774 & \\
\hline \multicolumn{7}{|l|}{ Model fit statistics } \\
\hline AIC & 1196.150 & & 1198.834 & & 1200.135 & \\
\hline Log-likelihood & -591.075 & & -590.417 & & -591.068 & \\
\hline Wald chi-square & 15.34 & 0.0090 & 16.50 & 0.0209 & 15.35 & 0.0318 \\
\hline $\mathrm{N}$ & 2224 & & 2224 & & 2224 & \\
\hline \# Rs & 139 & & 139 & & 139 & \\
\hline
\end{tabular}

ICC = intraclass correlation coefficient; AIC = Akaike information criterion

likely to have reported using marijuana. There were no significant interactions between current-day depression with gender or sexual orientation for current-day marijuana use.

Substance use with friends. Table 3 shows multilevel binary logistic regression models for current-day substance use with friends, where Model 1 included all covariates without interactions, and Models 2 and 3 included interactions between current-day depression with gender and sexual orientation, respectively. As shown in Model 1, females and heterosexual youths were $82 \%$ and $75 \%$ less likely to have reported using substances with their friends on the current day compared to their male and LGB counterparts, respectively. Models 2 and 3 revealed that there were no significant interactions between current-day depression and gender or sexual orientation for current-day substance use with friends, with one exception-LGB youths who failed to answer the depression question were more likely to use substances with friends than heterosexual youths who failed to answer this question (results not shown). 
Table 3. Adjusted odds ratio (AOR) and confidence intervals (CI) predicting current-day substance use with friends.

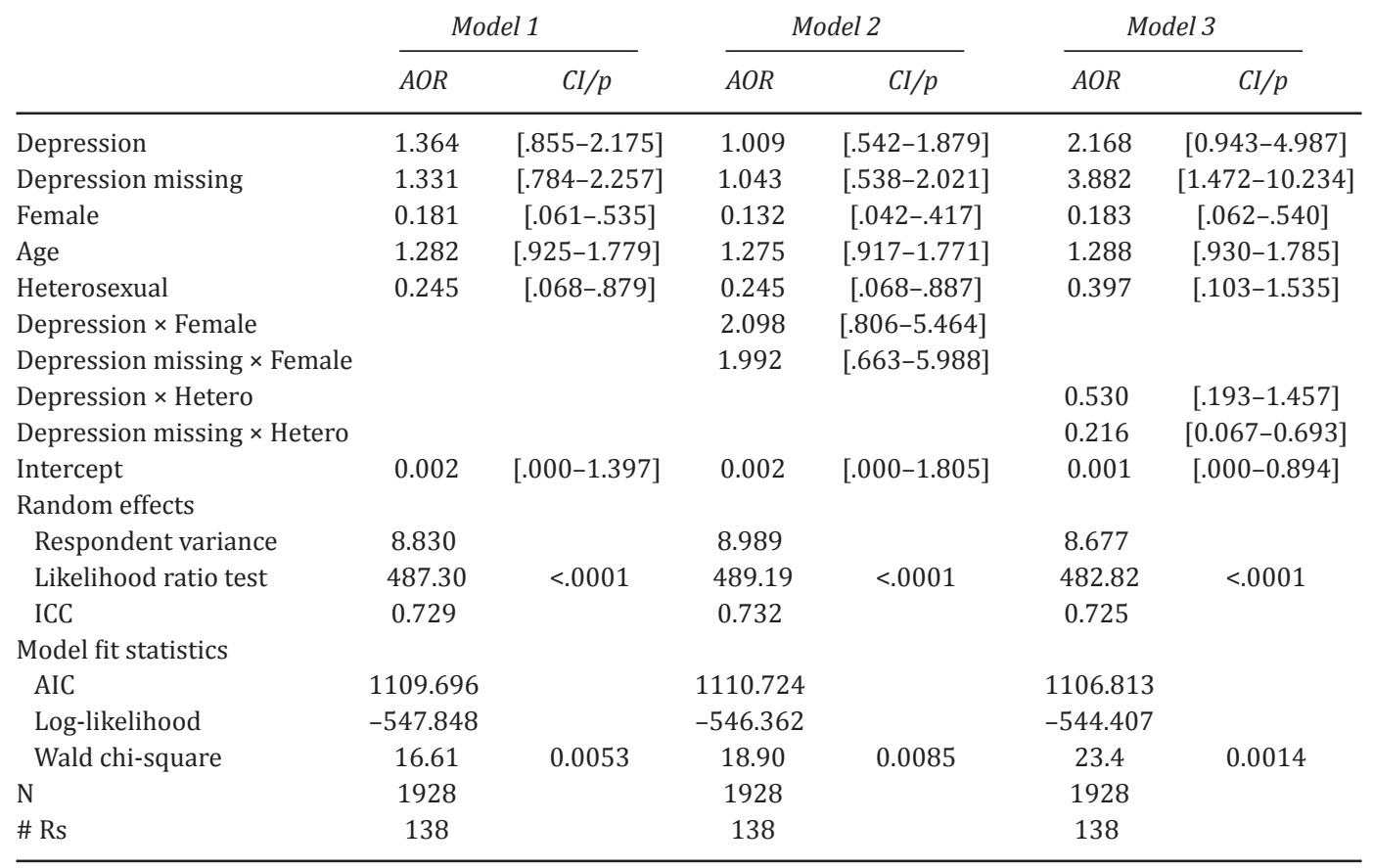

ICC = intraclass correlation coefficient; AIC = Akaike information criterion

\section{Discussion}

This study examined whether being depressed earlier in the day is associated with drinking alcohol, using marijuana, and using substances with friends later that day and whether this varies by gender and sexual orientation using EMA via SMS with homeless youths. Overall, we find that youths who report being depressed earlier in the day are more likely to report drinking alcohol later that day. Although females who are not depressed are less likely to drink alcohol than males, this gender difference disappears when both groups report being depressed. Moreover, although there is no difference in the probability of drinking by youth's sexual orientation when not depressed, we find that LGB youths are more likely to drink alcohol when they are depressed compared to their heterosexual counterparts. LGB youths are also more likely to use marijuana whereas males and LGB youths are more likely to report using substances with their friends compared to their counterparts. 
Regarding overall substance use, the current findings are consistent with the work of Santa Maria and colleagues (2018), who found that homeless youths report using marijuana most often in their study using EMA methodology. Our findings also are consistent with previous research, which finds a positive link between depression and substance use (Hadland et al., 2011; Lim et al., 2016). However, our study goes beyond prior retrospective studies and adds to this body of research by showing that the association between depression and drinking is time ordered. That is, youths who report feeling depressed earlier in the day are more likely to report drinking alcohol later that day compared to youths who do not report feeling depressed. We find no gender differences for marijuana use, which is consistent with the work of Wenzel and colleagues (2010). It is possible that using marijuana is a way that homeless youths cope with their current situation (Kidd \& Carroll, 2007) regardless of gender as prior research shows that marijuana is the most frequently used drug reported by homeless youths (Santa Maria et al., 2018).

We also find that males are more likely to report using substances with their friends compared to females. Because males use more substances (Santa Maria et al., 2018; Tyler, 2008b) and because peers are influential such that having more peers who use substances is positively associated with youths' own substance use (Rice et al., 2005; Tyler, 2008b; Wenzel et al., 2010), it is likely that males have a greater density of drug-using peers within their social network, which increases the likelihood that these males would use more drugs (Rice et al., 2005). LGB youths also report using substances with their friends more so than heterosexual youths. In addition to experiencing homelessness, it is possible that LGB youths also must contend with additional sources of stress such as discrimination, which may lead some LGB youths to turn to substance use to cope (Kidd \& Carroll, 2007) as well as rely on their peers for support, who may also be engaged in more frequent drug use.

Although we find gender differences such that males are more likely to drink alcohol compared to females, which is consistent with prior research (Santa Maria et al., 2018; Tyler, 2008b), this difference disappears when females report feeling depressed. In other words, when youths are depressed, they are more likely to report using alcohol later that day regardless of gender. Regarding sexual orientation, prior research finds that sexual minority homeless youths have higher levels of 
depressive symptoms (Tyler, 2008a) compared to heterosexual homeless youths, which is consistent with the current findings. Moreover, we find that although the probability of drinking is similar by sexual orientation when youths are not depressed, there is a higher probability of drinking among LGB youths when they are depressed compared to heterosexual youths. It is possible that due to their stigmatized status, LGB homeless youths may face more stigma and discrimination and these strains can increase the risk for negative health outcomes (Pearlin, 1999) including depression.

\section{Limitations, strengths, and future directions}

In terms of limitations, although we have some information from youths across 2,768 youth-days, we are missing substance use and depression data on between $20 \%$ and $30 \%$ of the youth-days, depending on the measure. Youths could answer the depression questions, but then not answer the substance use questions, and vice versa. These data appear to not be missing completely at random - failing to answer the depression question is differentially related to substance use with friends later that day for heterosexual and LGB youths. Second, the timing of the SMS question prompts captures the youths' experiences until that point but may have changed later that day. For example, the youth may have felt depressed or lonely after 4:00 p.m. or used substances after the 9:30 p.m. set of questions. Third, although youths were asked about a variety of different types of illicit drugs, only marijuana had sufficient levels of reports to examine individually among this group of youths. It is possible that a longer study period may have yielded more drug use.

Despite these limitations, our study has many strengths. To the best of our knowledge, this study is the first to use EMA via SMS with homeless youths to examine the links among depression, substance use, and using substances with friends based on daily data. Another strength is that we demonstrated that feeling depressed earlier in the day is a contributing factor to drinking alcohol later that day. Although we were unable to examine various other types of drugs given the insufficient levels of reports, future studies may wish to assess how feeling depressed is linked to illicit drug use. In addition, the finding that youths who feel depressed are more likely to consume alcohol suggests the need for "justin-time" interventions with this population. 
Specifically, researchers have noted the dearth of information on effective interventions (Slesnick, Guo, \& Brakenhoff, 2015), and have recently called for real-time risk assessments for substance use to inform the design of just-intime interventions delivered via smartphones (Santa Maria et al., 2018). Our findings also reveal that youths' likelihood of drinking not only varies by gender and sexual orientation but also depends on whether youths are feeling depressed earlier in the day. Future studies may wish to replicate our findings to see if similar associations for gender and sexual orientation are found with other samples of homeless youths. Our findings also have implications for service providers. If youths are using substances to cope with feeling depressed (Kidd \& Carroll, 2007), intervention programs that teach alternative coping strategies, such as counseling and developing problem-solving skills, may result in lowering their risk for alcohol and drug use. Because these youths often feel depressed and lonely, having supportive ties, positive role models, and other social supports can bolster youths' mental health (Tyler \& Schmitz, 2017). In addition, if youths can stay connected to home-based social relationships, they have a greater chance of reintegrating into society, as opposed to becoming embedded in risky street networks (Auerswald \& Eyre, 2002).

Overall, our study is an improvement over prior research as it provides a more nuanced understanding of the relationship between depression and drinking alcohol, the time ordering of these events, as well as how this relationship varies by gender and sexual orientation. EMA via SMS is a useful technique with homeless youths as we were able to capture data about their daily lives "as it occurred" (Shiffman et al., 2008) even though this is a highly mobile population (Tyler \& Whitbeck, 2004). Moreover, because EMA via SMS surveying verifies the timing of one behavior relative to another (Cohn et al., 2011), we could determine that feeling depressed occurred prior to youths' substance use. Furthermore, because this technique minimizes recall biases (Kuntsche \& Labhart, 2013), we could gather data on how youths were feeling each day, which allows for more specificity and allows us to control the timing of depression with alcohol and marijuana use.

Funding This article is based on research supported by a grant from the National Institute on Drug Abuse, No. DA036806, Dr. Kimberly A. Tyler, PI. 


\section{References}

Auerswald, C. L., \& Eyre, S. L. (2002). Youth homelessness in San Francisco: A life cycle approach. Social Science and Medicine, 54,1497-1512. doi:10.1016/ S0277-9536(01)00128-9

Bao, W. N., Whitbeck, L. B., \& Hoyt, D. R. (2000). Abuse, support, and depression among homeless and runaway adolescents. Journal of Health and Social Behavior, 41(4), 408-420. doi:10.2307/2676294

Bousman, C. A., Blumberg, E. J., Shillington, A. M., Hovell, M. F., Ji, M., Lehman, S., \& Clapp, J. (2005). Predictors of substance use among homeless youth in San Diego. Addictive Behaviors, 30(6), 1100-1110. doi:10.1016/j.addbeh.2004.10.006

Brown, S. M., Begun, S., Bender, K., Ferguson, K. M., \& Thompson, S. J. (2015). An exploratory factor analysis of coping styles and relationship to depression among a sample of homeless youth. Community Mental Health Journal, 51(7), 818-827. doi:10.1007/s10597-015-9870-8

Cochran, B. N., Stewart, A. J., Ginzler, J. A., \& Cauce, A. M. (2002). Challenges faced by homeless sexual minorities: Comparison of gay, lesbian, bisexual, and transgender homeless adolescents with their heterosexual counterparts. American Journal of Public Health, 92(5), 773-777. doi:10.2105/AJPH.92.5.773

Cohn, A. M., Hunter-Reel, D., Hagman, B. T., \& Mitchell, J. (2011). Promoting behavior change from alcohol use through mobile technology: The future of ecological momentary assessment. Alcoholism: Clinical and Experimental Research, 35(12), 2209-2215. doi:10.1111/j.1530-0277.2011.01571.x

Ennett, S. T., Bailey, S. L., \& Federman, E. B. (1999). Social network characteristics associated with risky behaviors among runaway and homeless youth. Journal of Health and Social Behavior, 40(1), 63-78. doi:10.2307/2676379

Hadland, S. E., Marshal, B. D., Kerr, T., Qi, J., Montaner, J. S., \& Wood, E. (2011). Depressive symptoms and patterns of drug use among street youth. Journal of Adolescent Health, 48(6), 585-590. doi:10.1016/j.jadohealth.2010.09.009

Kidd, S. A., \& Carroll, M. R. (2007). Coping and suicidality among homeless youth. Journal of Adolescence, 30(2), 283-296. doi:10.1016/j.adolescence.2006.03.002

Kipke, M. D., Montgomery, S. B., \& MacKenzie, R. G. (1993). Substance use among youth seen at a community-based health clinic. Journal of Adolescent Health, 14(4), 289-294. doi:10.1016/1054-139X(93)90176-P

Kuntsche, E., \& Labhart, F. (2013). Using personal cell phones for ecological momentary assessment: An overview of current developments. European Psychologist, 18(1), 3-11. doi:10.1027/1016-9040/a000127

Lim, C., Rice, E., \& Rhoades, H. (2016). Depressive symptoms and their association with adverse environmental factors and substance use in runaway and homeless youths. Journal of Research on Adolescence, 26(3), 403-417. doi:10.1111/ jora.12200 
Moore, H., Benbenishty, R., Astor, R. A., \& Rice, E. (2018). The positive role of school climate on school victimization, depression, and suicidal ideation among schoolattending homeless youth. Journal of School Violence, 17(3), 298-310. doi:10.108 0/15388220.2017.1322518

National Center for Homeless Education. The (NCHE) and the National Association for the Education of Homeless Children and Youth (NAEHCY). (2017). Updated Definitions of Homelessness for Federal Programs Serving Children, Youth, and Families. Retrieved from https://nche.ed.gov/downloads/briefs/introduction.pdf

National Network for Youth. (2018). How many homeless youth are in America? Retrieved May 4, 2018 from https://www.nn4youth.org/learn/ how-many-homeless/

Nyamathi, A., Marfisee, M., Slagle, A., Greengold, B., Liu, Y., \& Leake, B. (2012). Correlates of depressive symptoms among homeless young adults. Western Journal of Nursing Research, 34(1), 97-117. doi:10.1177/0193945910388948

Pearlin, L. (1999). Stress and mental health: A conceptual overview. In A. V. Horwitz \& T. L. Scheid (Eds.), A handbook for the study of mental health: Social contexts, theories, and systems (pp. 161-175). New York, NY: Cambridge University Press.

Rice, E., Milburn, N. G., Rotheram-Borus, M. J., Mallett, S., \& Rosenthal, D. (2005). The effects of peer group network properties on drug use among homeless youth. American Behavioral Scientist, 48(8), 1102-1123. doi:10.1177/0002764204274194

Santa Maria D., Padhye, N., Yang, Y., Gallardo, K., Santao, G. M., Jung, J., \& Businelle, M. (2018). Drug use patterns and predictors among homeless youth: Results of an ecological momentary assessment. The American Journal of Drug and Alcohol Abuse, 44, 551-560. doi:10.1080/00952990.2017.1407328

Shiffman, S., Stone, A. A., \& Hufford, M. R. (2008). Ecological momentary assessment. Annual Review of Clinical Psychology, 4(1), 1-32. doi:10.1146/annurev. clinpsy.3.022806.091415

Slesnick, N., Guo, X., Brakenhoff, B., \& Bantchevska, D. (2015). Comparison of three interventions for homeless youth evidencing substance use disorders: Results of a randomized clinical trial. Journal of Substance Abuse Treatment, 54, 1-13. doi:10.1016/j.jsat.2015.02.001

Stewart, A. J., Steiman, M., Cauce, A. M., Cochran, B. N., Whitbeck, L. B., \& Hoyt, D. R. (2004). Victimization and posttraumatic stress disorder among homeless adolescents. Journal of the American Academy of Child and Adolescent Psychiatry, 43, 325-331. doi:10.1097/00004583-200403000-00015

Substance Abuse and Mental Health Services Administration. (2016). Behavioral health and homelessness resources. Retrieved from https://www.samhsa.gov/ homelessness-programs-resources/hpr-resources/youth Retrieved June 12, (2017).

Thompson, S. J. (2005). Risk/protective factors associated with substance use among runaway/homeless youth utilizing emergency shelter services nationwide. Substance Abuse, 25(3), 13-26. doi:10.1300/J465v25n03_02 
Thompson, S. J., Bender, K., Ferguson, K. M., \& Kim, Y. (2015). Factors associated with substance use disorders among traumatized homeless youth. Journal of Social Work Practice in the Addictions, 15(1), 66-89. doi:10.1080/15332 56X.2014.996229

Tompsett, C. J., Domoff, S. E., \& Toro, P. A. (2013). Peer substance use and homelessness predicting substance abuse from adolescence through early adulthood. American Journal of Community Psychology, 51(3-4), 520-529. doi:10.1007/s10464-013-9569-3

Tyler, K. A. (2008a). A comparison of risk factors for sexual victimization among gay, lesbian, bisexual, and heterosexual homeless young adults. Violence and Victims, 23(5), 586-602. doi:10.1891/0886-6708.23.5.586

Tyler, K. A. (2008b). Social network characteristics and risky sexual and drug related behaviors among homeless young adults. Social Science Research, 37(2), 673685. doi:10.1016/j.ssresearch.2007.09.004

Tyler, K. A., \& Schmitz, R. M. (2017). Using cell phones for data collection: Benefits, outcomes, and intervention possibilities with homeless youth. Children and Youth Services Review, 76, 59-64. doi:10.1016/j.childyouth.2017.02.031

Tyler, K. A., Schmitz, R. M., \& Ray, C. M. (2018). Role of social environmental factors on anxiety and depressive symptoms among Midwestern homeless youth. Journal of Research on Adolescence, 28(1), 199-210. doi:10.1111/jora.12326

Tyler, K. A., \& Whitbeck, L. B. (2004). Lost childhoods: Risk and resiliency among runaway and homeless adolescents. In P. Allen-Meares \& M. W. Fraser (Eds.), Intervention with children and adolescents: An interdisciplinary perspective (pp. 378-397). Boston, MA: Pearson Education.

Walls, N. E., \& Bell, S. (2011). Correlates of engaging in survival sex among homeless youth and young adults. Journal of Sex Research, 48(5), 423-436. doi:10.1080/00 224499.2010.501916

Wenzel, S. L., Tucker, J. S., Golinelli, D., Green, H. D., Jr., \& Zhou, A. (2010). Personal network correlates of alcohol, cigarette, and marijuana use among homeless youth. Drug and Alcohol Dependence, 112(1-2), 140-149. doi:10.1016/j. drugalcdep.2010.06.004 